\title{
Hybrid layers of etch-and-rinse versus self-etching adhesive systems
}

\author{
Alberto Albaladejo ${ }^{1}$, Raquel Osorio ${ }^{2}$, Manuel Toledano ${ }^{2}$, Marco Ferrari ${ }^{3}$ \\ ${ }^{1}$ Associate professor of Orthodontic, Faculty of Dentistry, University of Salamanca, Spain \\ ${ }^{2}$ Professor of Dental Materials, Faculty of Dentistry, University of Granada, Spain \\ 3 Professor of Dental Materials and Restorative Dentistry, Policlinico "Le Scotte", University of Siena, Italy
}

Correspondence:

Facultad de Medicina y Odontología,

Departamento de Cirugía.

C/Alfonso X el Sabio $S / N$.

C.P. 37007 Salamanca. Spain

albertoalbaladejo@usal.es

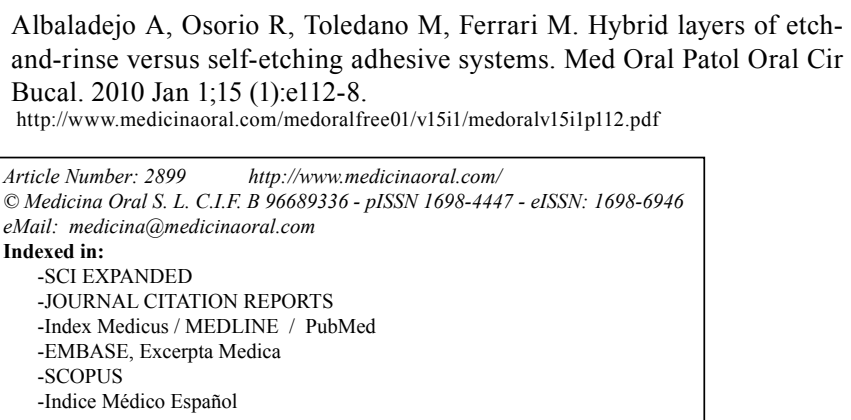

\begin{abstract}
Objective: To evaluate the effectiveness in the formation of resin tags, adhesive lateral branches and hybrid layers of five adhesive systems, when bonding to dentine. Material and Methods: Flat dentin surfaces from 25 molars were bonded with several adhesive systems according to the manufacturers' instructions. Composite build-ups were constructed incrementally with Tetric Ceram. The Specimens were sectioned parallel to the long axis. One section was treated with phosphoric acid and sodium hypochlorite in order to reveal the hybrid layer formation. The other section was stored in 30\% hydrochloric acid to detect resin tags and adhesive lateral branch formation. Results: The two etch-and-rinse self-priming adhesives exhibited thicker hybrid layers than those found in self-etching adhesive systems. The all-in-one adhesive showed droplet formation between the adhesive and the resin composite. The resin tags formed with the etch-and-rinse adhesives were much longer than those found with the self-etching adhesives. Lateral branch formation was observed in etch-and-rinse adhesives and in one of the self-etch adhesives Clearfil SE Bond (SEB). Conclusion: The formed hybrid layer obtained with the two-step selfetching adhesives and the etch-and-rinse systems were continuous and uniform in thickness. Droplets within the all-in-one adhesive layer may occur as a result of water absorption from dentin through osmosis, and may interfere with proper resin polymerization. Resin tags obtained with SEB and the etch-and-rinse adhesive systems showed lateral branches, which is a sign of proper resin infiltration.
\end{abstract}

Key words: Dentin, bonding, scanning electron microscopy. 


\section{Introduction}

The infiltration of demineralized collagen fibers with resin permits formation of hybrid layers with resin tags and adhesive lateral branches, thus creating micromechanical retention of the resin to the demineralized substrate $(1,2)$. The micromechanical retention is the chief mechanism for resin bonding to dentin. Resin penetration into the intertubular dentin seems to be of major factor influencing bond strength (2).

Dentin bonding systems have been improved in order to promote the durability and reliability of adhesive restorations (3). Two main strategies are used to create durable dentin bonding: 1) etch-and-rinse systems (Single Bond -SB-, Prime and Bond NT -PBNT-) work by removing the smear layer with phosphoric acid, followed by the application of a primer and an adhesive in the same step leading to infiltrate dentin (1); and 2) the selfetching approach, in which the acid and the primer are combined in one solution to form an acidic monomer (1) and a final bonding step is later applied (Clearfil SE Bond -SEB-, Protect Bond-PB-). The etching potential of self-etch bonding systems induces the formation of a hybridized complex comprising a surface zone made up of the hybridized smear layer with a true hybrid layer underneath $(2,4)$. Self-etch all-in-one adhesives have also been introduced, and contain all components in just one solution (Etch \& Prime -EP-).

One of the first and most widely used tools to evaluate qualitatively bonding to dentin is the scanning electron microscope (SEM) (5).

Thus, the objective of this study was to evaluate the hybrid layer, resin tags and adhesive lateral branches formations of five adhesive systems bonded to dentin, describing morphological characteristics and ascertaining probable relationships with the bonding performance of these adhesive systems. The null hypothesis to be tested is that there are not differences in the histomorphologic appearance of the dentin-adhesive bonded interfaces of five evaluated adhesive systems.

\section{Materials and Methods}

Twenty five extracted human third molars that were stored in $0.5 \%$ chloramine at $4{ }^{\circ} \mathrm{C}$ and were used within one month after extraction. The specimens were sectioned below the dentinoenamel junction and ground flat with 180 -grit silicon carbide abrasive papers under running water to provide uniform and smear layer covered surfaces. Two etch-and-rinse self-priming adhesives (Single Bond -SB-, 3M ESPE, St. Paul, MN, USA; Prime \& Bond NT -PNT-, Dentsply DeTrey, Konstanz, Germany), two two-step self-etching adhesives (Clearfil SE Bond -SEB-, Kuraray Medical Inc., Tokyo, Japan; Protect Bond -PB- Kuraray Medical Inc., Tokyo, Japan), and one all-in-one self-etch adhesive (Etch \& Prime 3.0 -EP-, Dentsply Degussa AG, Hanau, Ger- many) were used. They were bonded to dentin surfaces according to the manufacturers' instructions (Table 1). After bonding, composite build-ups, each $3 \mathrm{~mm}$ in height, were constructed incrementally $(1.5 \mathrm{~mm})$ with a light-cured microhybrid resin composite (Tetric Ceram, Ivoclar-Vivadent, Schäan, Liechtenstein). Each layer of the composite was light-activated for 40 seconds with a Translux EC halogen light-curing unit (Heraeus-Kulzer $\mathrm{GmbH}$, Hanau, Germany). Light intensity output was monitored with a Demetron Curing Radiometer (Model 100 Demetron Research Corporation, Danbury, CT, USA) to be at least $600 \mathrm{~mW} / \mathrm{sec}$.

The specimens were sectioned parallel to the long axis using a diamond saw wheel (Isomet, Buehler, Lake Bluff, NY, USA) at slow speed under water coolant. One section of each specimen was stored in water solution at room temperature. After 24 hours, the section was gently decalcified (32\% phosphoric acid was applied for 30 seconds, washed and gently air-dried) and $2 \%$ sodium hypochlorite was applied onto the surface solution for 120 seconds in order to evaluate the hybrid layer and resin tags formations.

After being extensively rinsed with water, the specimens were dried by immersion in solutions in ascending alcohol concentrations. Impressions were taken and replica models prepared using epoxy resin. Specimens and replicas were sputter-coated with gold (Edwards Ltd., London, UK) and observed with SEM (Philips 505 , Eindoven, The Nertherlands) at different standardized magnifications (X2000, X 2500, X 3000).

The other section of each sample was stored in $30 \%$ clorhidric acid for 48 hours and washed for 20 minutes in $2 \%$ sodium hypochlorite in order to completely dissolve the dental substrate, resin tags and adhesive lateral branch formation may be easily observed. These specimens processed for SEM observation. SEM photomicrographs at X500, X800, X2000 and X3000 original magnification were taken.

Following features were evaluated at the SEM images: 1) formation and uniformity of the hybrid layer along the entire length of the adhesive interface; 2) resin tags formation; 3) existence of lateral branches from the resin tags.

\section{Results}

Hybrid layer observation: All the adhesive systems showed hybrid layer formation. Self-etching adhesive systems SEB and PB produced a hybridized complex of similar thickness (Fig. 1A and Fig. 1B). EP resulted in a thicker hybridized complex (Fig. 1C). At the interface between the hybridized complex and the composite restoration was possible to see frequent droplets formation were observed (Fig. 1C). PBNT and SB exhibited similar morphology under SEM, hybrid layers of these etch-and-rinse systems were thicker (Fig. 1D) than those found in self-etching adhesive systems. 
Table 1. Mode of Application, compositions, and manufacturers of tested adhesives.

\begin{tabular}{|c|c|c|c|}
\hline Materials & Components & Mode/steps of application & Manufacturer \\
\hline $\begin{array}{l}\text { Single Bond } \\
\text { Total-etch } \\
\text { Self-priming }\end{array}$ & $\begin{array}{l}\text { 2-hydroxyethylmethacrylate; } \\
\text { water; ethanol; Bis-GMA; } \\
\text { dimethacrylates; amines; } \\
\text { methacrylate-functional; } \\
\text { copolymer of polyacrylic and } \\
\text { polyitaconic acids. }\end{array}$ & $\begin{array}{l}\text { Etch for } 15 \text { seconds. Rinse with water spray } \\
\text { for } 10 \text { seconds, leaving tooth moist. Apply two } \\
\text { consecutive coats of the adhesive with a fully } \\
\text { saturated brush tip. Dry gently for } 2-5 \text { sec- } \\
\text { onds. Light cure for } 10 \text { seconds. }\end{array}$ & $\begin{array}{l}\text { 3M, St.Paul, MN, } \\
\text { USA. } \\
\text { Lot. } 4242 .\end{array}$ \\
\hline $\begin{array}{l}\text { Prime \& Bond NT } \\
\text { Total-etch } \\
\text { Self-priming }\end{array}$ & $\begin{array}{l}\text { PENTA; UDMA resin; resin } \\
\text { R5-62-1; T-resin; D-resin; } \\
\text { nanofiller; initiators; stabilizer; } \\
\text { cetylamine hydrofluoride; ac- } \\
\text { etone; hydroxyethylmethacry- } \\
\text { late. }\end{array}$ & $\begin{array}{l}\text { Etch for } 15 \text { seconds. Rinse with water spray } \\
\text { for } 15 \text { seconds and remove water with a soft } \\
\text { blow of air. Leave a moist surface. Apply } \\
\text { ample amounts of the adhesive to saturate the } \\
\text { surface, reapply if it is necessary. Leave the } \\
\text { surface undisturbed for } 20 \text { seconds. Remove } \\
\text { solvent by blowing gently with air for at least } \\
5 \text { seconds. Light cure for } 10 \text { seconds. }\end{array}$ & $\begin{array}{l}\text { Dentsply / De Trey } \\
\text { GmbH, Konstanz, } \\
\text { Germany. } \\
\text { Lot. } 0209000918 .\end{array}$ \\
\hline $\begin{array}{l}\text { Clearfil SE Bond } \\
\text { Self-etch } \\
\text { 2-steps }\end{array}$ & $\begin{array}{l}\text { Primer: 10-methacryloy- } \\
\text { loxydecyl dihydrogen phos- } \\
\text { phate; 2-hydroxyethyl meth- } \\
\text { acrylate; hydrophilic dime- } \\
\text { thacrylate; } \\
\text { camphorquinone; N,N-dietha- } \\
\text { nol-p-toluidine, water. } \\
\text { Bond: 10-methacryloyloxyde- } \\
\text { cyldihydrogen phosphate; } \\
\text { N,N-diethanol-p-toluidine; } \\
\text { 2-hydroxyethylmethacrylate; } \\
\text { Bis-phenol A diglycidyl- } \\
\text { methacrylate; silanated colloi- } \\
\text { dal silica; hydrophobic dime- } \\
\text { thacrylate; camphorquinone. }\end{array}$ & $\begin{array}{l}\text { Apply Primer for } 20 \text { seconds. Mild air stream. } \\
\text { Apply Bond. Gentle air stream. Light cure for } \\
10 \text { seconds. }\end{array}$ & $\begin{array}{l}\text { Kuraray Co, Osaka, } \\
\text { Japan. } \\
\text { Lot. } 390 .\end{array}$ \\
\hline $\begin{array}{l}\text { Etch \& Prime } 3.0 \\
\text { Self-etch } \\
\text { 1-step }\end{array}$ & $\begin{array}{l}\text { Universal: 2-hydroxyethyl- } \\
\text { methacrylate; water; ethanol } \\
\text { Catalyst: Tetramethacrylocy- } \\
\text { ethylpyrophosphate. }\end{array}$ & $\begin{array}{l}\text { Mix Etch \& Prime } 3.0 \text { Universal and Catalyst. } \\
\text { Apply for } 30 \text { seconds. Air blow gently. Light } \\
\text { cure for } 10 \text { seconds. Repeat the above men- } \\
\text { tioned steps. }\end{array}$ & $\begin{array}{l}\text { Degussa AG, Hanau, } \\
\text { Germany. } \\
\text { Lot.019920. }\end{array}$ \\
\hline $\begin{array}{l}\text { Protect Bond } \\
\text { Self-etch } \\
\text { 2-steps }\end{array}$ & $\begin{array}{l}\text { Primer: hydroxyethyl- } \\
\text { methacrylate; hydrophilic } \\
\text { dimethacrylate; 10-meth- } \\
\text { acryloyloxydecyldihydrogen } \\
\text { phosphate; N,N-diethanol } \\
\text { p-toluidine; camphorquinone; } \\
\text { water. } \\
\text { Bond: Silanated silica; Bis- } \\
\text { GMA; hydroxyethylmethacry- } \\
\text { late; hydrophilic dimethacry- } \\
\text { late; 10- methacryloyloxyde- } \\
\text { cyldihydrogen phosphate; } \\
\text { toluidine; camphorquinone; } \\
\text { MDPB; sodium fluoride. }\end{array}$ & $\begin{array}{l}\text { Apply Primer for } 20 \text { seconds. Mild air stream. } \\
\text { Apply Bond. Gentle air stream. Light cure for } \\
10 \text { seconds. }\end{array}$ & $\begin{array}{l}\text { Kuraray Co, Osaka, } \\
\text { Japan. } \\
\text { Primer. Lot. } 000001 \\
\text { Bond. Lot } 000002\end{array}$ \\
\hline
\end{tabular}

PENTA= penta-acrylate ester; TEGDMA= triethylene glycol-dimethacrylate; Bis-GMA= bysphenyl glycidyl methacrylate, UDMA= urethane dimethacrylate; $\mathrm{BHT}=$ butylated hydroxyl toluene; TCB resin = carboxylic acid modified dimethacrylate. MDPB: 12-methacryloyloxydodecylpyridium bromide. 


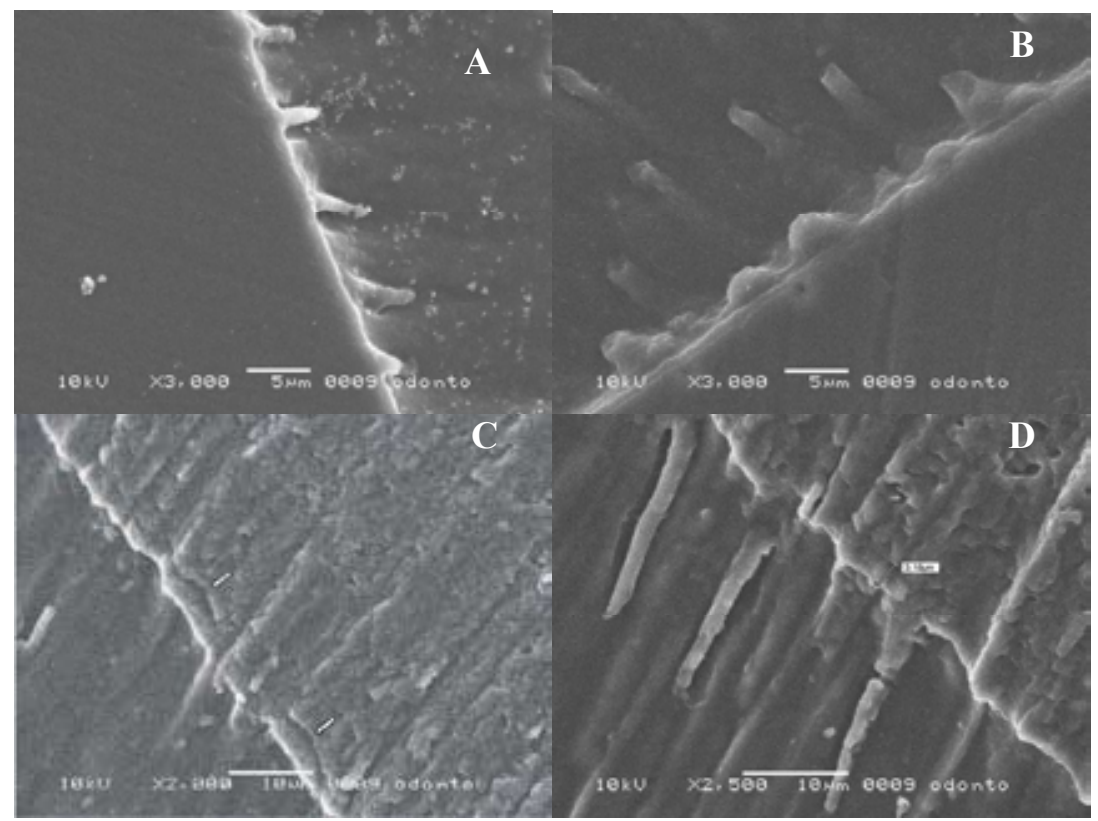

Fig. 1. Hybridized complexes and hybrid layers formed with self-etching and etch-and-rinse adhesive systems. 1A: SEB dentin bonding interface (original magnification: $S E M \times 3000$ ); $1 \mathrm{~B}$ : $\mathrm{PB}$ dentin bonding interface (original magnification: $\mathrm{SEM} \times 3000$ ); $1 \mathrm{C}$ : $\mathrm{EP}$ dentin bonding interface. Droplets (arrows) can be observed between the adhesive and the composite (original magnification: SEM $\times 2000$ ); 1D: PNT dentin bonding interface (original magnification: SEM $\times 2500$ ).

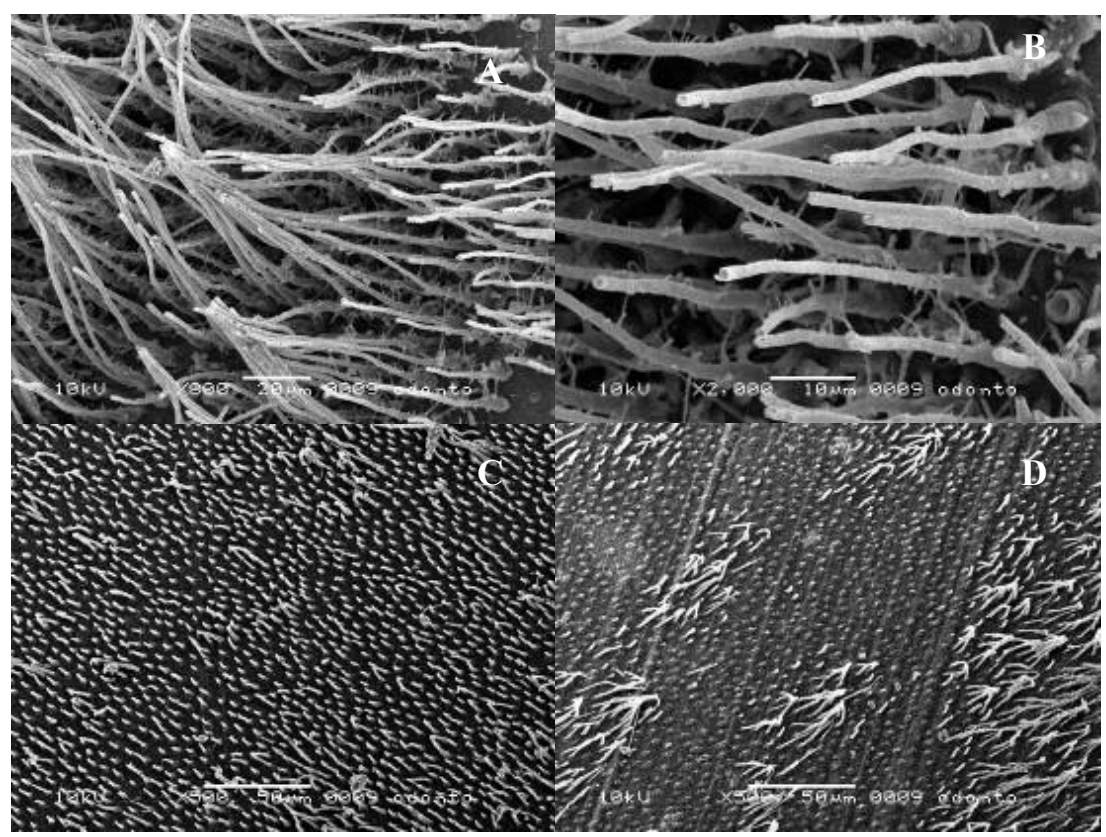

Fig. 2. Resin tags observed with self-etching adhesives. 2A: SEB dentin bonding interface (original magnification: SEM $\times 800$ ); 2 B: SEB dentin bonding interface. Small lateral branches on the sides of the resin tags are observed (original magnification: $\mathrm{SEM} \times 2000$ ); $2 \mathrm{C}$ : PB dentin bonding interface (original magnification: $\mathrm{SEM} \times 500$ ); $2 \mathrm{D}$ : EP dentin bonding interface (original magnification: $\mathrm{SEM} \times 500)$. 


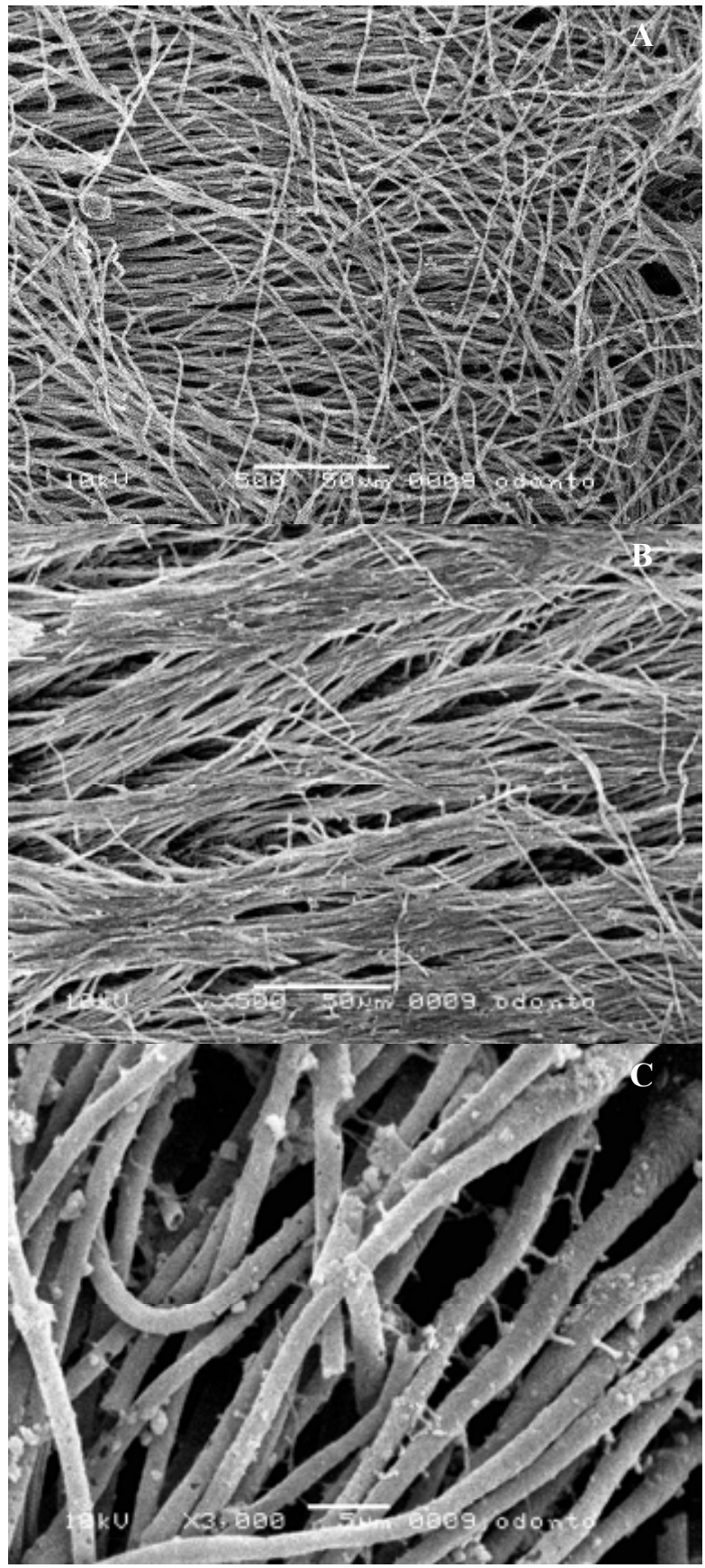

Fig. 3. Resin tags observed with etch-and-rinse adhesives. 3A: PBNT dentin bonding interface (original magnification: SEM $\times 500$ ); $3 \mathrm{~B}$ : SB dentin bonding interface. Adhesive lateral branches are detectable (original magnification: SEM $\times 500$ ); $3 \mathrm{C}$ : PBNT dentin bonding interface. Numerous small lateral extensions of microtags branching off at angles from the main resin tags are visible (original magnification: $\mathrm{SEM} \times 3000$ ).
Resin tag formation: SEB showed resin tags that were narrow and regularly shaped with conical swelling at their bases (Fig. 2A). Small lateral branches were sporadically observed on the sides of the resin tags (Fig. 2B). When PB and EP were employed for bonding, the tags were wide, short and funnel shaped, with no lateral branches (Fig. 2C, 2D). The resin tags formed with etch-and-rinse self-priming adhesives PBNT and SB had conical swelling at their bases (Fig. 1D). Observed resin tags in both etch-and-rinse adhesives (Fig. 3A, 3B) were much frequent and longer than those found in samples bonded with self-etching adhesives. These tags showed numerous small lateral extensions of microtags branching off at right angles from the main resin tags (Fig. 3C).

\section{Discussion}

There are some morphological differences between the created bond structures when using etch-and-rinse bonding systems (Fig. 1D) or self-etch adhesives. The null hypothesis is rejected. The most remarkable difference is the hybrid layer thickness (1). Hybrid layers created by the two etch-and-rinse self-priming adhesives were thicker than those observed in the specimens bonded with self-etching adhesive systems (Fig. 1A1D). Despite the physical appearance of thin hybridized complex, high immediate bond strength has been reported for these self-etching systems $(1,3)$. This suggests the absence of correlation between hybrid layer thickness and bonding efficacy as long as a uniform demineralization front is created at the underlying dentin and it is fully impregnated by resin (6).

Earliest commercial versions of self-etch bonding systems were hydrophobic, which did not allow them to adapt to dentin properly. The adhesive must be able to diffuse and penetrate in an aqueous environment and, therefore, should be hydrophilic in nature (7). The tested self-etching adhesives (SEB, PB) contain acid monomers, often mixed with water, to make the adhesive systems sufficiently acid to form hibridized complex (similar in thickness), penetrate the smear layer and interact with the underlying dentin about $0.5 \mathrm{~m}$ (Fig. 1A and Fig. 1B) $(6,8)$. PB bonding formulation is similar to that of SEB. Both self-etching adhesive systems contain 10-MDP monomer (highly hydrophilic), which is supposed to interact chemically with hydroxyapatite that remains available at the partially demineralized dentin surface (9). Moreover, MDP improves the wetting of the tooth surface, causes minimal dissolution of smear plugs and limited opening of tubules, which reduces dentin permeability and facilitates penetration, impregnation, polymerization and entanglement of monomers with the underlying dentin to form hybridized complexes $(1,3,8)$.

The self-etching adhesives vary in their acidity by vir- 
tue of the composition and concentration of polymerizable acids and acidic resin monomers in these systems (8). However, it seems that the $\mathrm{pH}$ value of self-etching adhesives does not influence the morphology of the dentin-resin interfaces (7). The $\mathrm{pH}$ is not a determinant factor conditioning the action of self-etching adhesives (7), and the attained bond strength is affected by the adhesive's acidity if a $\mathrm{pH}$ value of approximately 2 is reached by the adhesive (8).

The all-in-one adhesive EP showed a thick hybridized complex (Fig. 1C) being able to completely dissolve the smear layer, ( $\mathrm{pH} 0.6)$ and to forming a relatively thick hybridized complex (1). When this HEMA-rich adhesive dentin interface was evaluated, many separation zones located near the adhesive resin-composite interface were systematically observed (Fig. 1C). These separation zones, resembling droplets, were found systematically at EP's specimens. These droplets seem to be the result from water absorption from dentin through osmosis $(10,11)$, and this water is transmitted from dentin following a diffusion process $(10,12)$. The location of the droplets near the adhesive resin-composite interface indicates that a "hypertonic" (high concentration of molecules and low concentration of water solution is present here) (11). The low molecular weight and the strong hydrophilic character of HEMA explain why osomosis occurs in EP. It will result in a fragile zone jeopardizing bond effectiveness and durability (13).

The thickness of the hybrid layer produced by SB and PBNT was approximately 3 to $4 \mu \mathrm{m}$ according to previous studies $(1,14)$. The hybrid layer formed by the two etch-and-rinse adhesive systems (Fig. 1D), was compact and homogenous in thickness (1). Bis-GMA, HEMA and polyalkenoic acid are the main chemical components of the SB. An aqueous HEMA solution promotes the impregnation of resin into the exposed collagen $(15,16)$. On the other hand, PBNT contains PENTA, an acidic phosphonated monomer, which could have some kind of interaction within the calcium ions left on the dentin surface, or even at the underlying dentin (3).

When SEB was applied, formed resin tags were much longer than those formed by EP or by PB (Fig. 2A-2D). In these dentin-bonded interfaces, the contribution of the resin tags to the bond strength, relative to the role of the intertubular dentin may vary depending on the tested dentin bonding agent, the orientation of the dentinal tubules and the dentin depth $(17,18)$. The penetration of resin tags into the dentinal tubules is believed to contribute little to the final bond strength $(2,17,19)$, but the adaptation to the inner tubule walls probably contributes significantly much more to bonding efficacy (17). Formed resin tags after SEB application (Fig. 2A) were numerous and had conical swelling at their bases, which may be considered as sign of a good seal (8). SEB showed adhesive small lateral branches (Fig.
2B) sporadically observed on the sides of the resin tags, indicating that resin attempted to fill lateral canals. A supplementary retention and sealing is offered by the formation of micro-tags in the lateral canal branch from the main tubules (20). EP showed short and funnel shaped tags with no lateral braches (Fig. 2D), even when it has been stated that produced a deeper etching compared with SEB (pH 1.9), and tubule entrances were not only opened but also enlarged (1).

The resin tags formed with the tested etch-and-rinse adhesives, PBNT and SB (Fig. 3A and Fig. 3B) were much longer than those found in samples bonded with self-etching adhesives and both had marked conical swelling at their bases, as a result of the removal of the peritubular dentin by the previous acid etching of dentin (Fig. 1D). PBNT and SB formed resin tags revealed numerous small lateral extensions of microtags branching off at right angles from the main resin tags (Fig. 3C), which is a clear sign of proper adaptation and sealing $(1,3)$.

Formed hybrid layers with the two-step self-etch adhesive systems and both etch-and-rinse bonding agents were continuous and uniform in thickness. The all-inone adhesive showed droplets between the adhesive and the resin composite which could jeopardize bond strength and durability. All adhesive systems showed resin tags formation. Resin tags obtained with the twostep self-etching adhesive system (SEB) and the etchand-rinse adhesive systems had conical swelling at their bases and showed lateral branches, a sign of proper dentin infiltration.

\section{References}

1. Osorio R, Toledano M, De Leonardi G, Tay F. Microleakage and interfacial morphology of self-etching adhesives in class $\mathrm{V}$ resin composite restorations. J Biomed Mater Res B Appl Biomater. 2003;66:399-409.

2. Van Meerbeek B, Inokoshi S, Braem M, Lambrechts P, Vanherle G. Morphological aspects of the resin-dentin interdiffusion zone with different dentin adhesive systems. J Dent Res. 1992;71:1530-40.

3. Toledano M, Osorio R, Albaladejo A, Aguilera FS, Osorio E. Differential effect of in vitro degradation on resin-dentin bonds produced by self-etch versus total-etch adhesives. J Biomed Mater Res A. 2006;77:128-35.

4. Tay FR, Carvalho R, Sano H, Pashley DH. Effect of smear layers on the bonding of a self-etching primer to dentin. J Adhes Dent. 2000;2:99-116.

5. Van Meerbeek B, Vargas M, Inoue S, Yoshida Y, Perdigão J, Lambrechts $\mathrm{P}$, et al. Microscopy investigations. Techniques, results, limitations. Am J Dent. 2000;13:3D-18D.

6. Tay FR, Pashley DH. Aggressiveness of contemporary self-etching systems. I: Depth of penetration beyond dentin smear layers. Dent Mater. 2001;17:296-308.

7. Grégoire G, Millas A. Microscopic evaluation of dentin interface obtained with 10 contemporary self-etching systems: correlation with their pH. Oper Dent. 2005;30:481-91.

8. Tay FR, Sano H, Carvalho R, Pashley EL, Pashley DH. An ultrastructural study of the influence of acidity of self-etching primers and smear layer thickness on bonding to intact dentin. J Adhes Dent. 2000;2:83-98.

9. Nunes TG, Polido M, Amorim A, Nunes SG, Toledano M. Multi- 
nuclear magnetic resonance studies on the chemical interaction of a self-etching adhesive with radicular and coronal human dentin. J Mater Sci Mater Med. 2007;18:2093-9.

10. Tay FR, Pashley DH, Suh BI, Carvalho RM, Itthagarun A. Singlestep adhesives are permeable membranes. J Dent. 2002;30:371-82.

11. Van Landuyt KL, Snauwaert J, Peumans M, De Munck J, Lambrechts P, Van Meerbeek B. The role of HEMA in one-step self-etch adhesives. Dent Mater. 2008;24:1412-9.

12. Sauro S, Pashley DH, Mannocci F, Tay FR, Pilecki P, Sherriff $\mathrm{M}$, et al. Micropermeability of current self-etching and etch-andrinse adhesives bonded to deep dentine: a comparison study using a double-staining/confocal microscopy technique. Eur J Oral Sci. 2008;116:184-93.

13. Monticelli F, Ferrari M, Toledano M. Cement system and surface treatment selection for fiber post luting. Med Oral Patol Oral Cir Bucal. 2008;13:E214-21.

14. Frankenberger R, Perdigão J, Rosa BT, Lopes M. "No-bottle" vs "multi-bottle" dentin adhesives--a microtensile bond strength and morphological study. Dent Mater. 2001;17:373-80.

15. Nakabayashi N, Saimi Y. Bonding to intact dentin. J Dent Res. 1996;75:1706-15

16. Sano H, Shono T, Takatsu T, Hosoda H. Microporous dentin zone beneath resin-impregnated layer. Oper Dent. 1994;19:59-64.

17. Tam LE, Pilliar RM. Fracture surface characterization of dentin-bonded interfacial fracture toughness specimens. J Dent Res. 1994;73:607-19.

18. Staninec M, Nguyen H, Kim P, Marshall GW, Rithchie RO, Marshall SJ. Four-point bending evaluation of dentin-composite interfaces with various stresses. Med Oral Patol Oral Cir Bucal. 2008;13:E81-4.

19. Tagami J, Tao L, Pashley DH. Correlation among dentin depth, permeability, and bond strength of adhesive resins. Dent Mater. 1990;6:45-50.

20. Mjör IA, Nordahl I. The density and branching of dentinal tubules in human teeth. Arch Oral Biol. 1996;41:401-12. 